\title{
Comparative analysis of self-reliance of athletes of different sports
}

\author{
Kolosov A.B. ${ }^{1 \mathrm{ABDE}}$, Volianiuk N.Yu. ${ }^{2 \mathrm{ABCDE}}$, Lozhkin G.V. ${ }^{3 \mathrm{ABDE}}$, Buniak N.A. ${ }^{4 \mathrm{ADE}}$, Osodlo V.I. ${ }^{5 \mathrm{ACDE}}$
}

${ }^{1}$ Laboratory of Current and Operative Control of National Teams'Performance, State Scientific Research Institute of Physical Culture and Sports, Kyiv, Ukraine

${ }^{2,3}$ Department of Psychology and Pedagogy, National Technical University of Ukraine «Igor Sikorsky Kyiv Polytechnic Institute», Kyiv, Ukraine

${ }^{4}$ Department of Psychology in production Ternopil Ivan Puluj National Technical University, Ternopil, Ukraine

${ }^{5}$ Social Studies Institute, National Defence University of Ukraine named after Ivan Cherniakhovskyi, Kyiv, Ukraine

Authors' Contribution: A - Study design; B - Data collection; C - Statistical analysis; D - Manuscript Preparation; E - Funds Collection.

\begin{tabular}{|c|c|}
\hline \multicolumn{2}{|l|}{ Abstract } \\
\hline Purpose: & $\begin{array}{l}\text { The purpose of the study is to identify self-reliance manifestation features among qualified athletes of } \\
\text { different sports. }\end{array}$ \\
\hline Material: & $\begin{array}{l}\text { The study participants were representatives of combat sports (boxing) } n=23 \text {, complex-coordination } \\
\text { (gymnastics) } n=25 \text {, speed-strength (discus throw) } n=23 \text {, and also cyclic sports (swimming) } n=38 \text {. In } \\
\text { total } 109 \text { sportsmen. The age of the respondents was from } 16 \text { to } 18 \text { years old. Comprehensive psycho- } \\
\text { diagnostic methods diagnose self-reliance level and manifestation degree of athletes' personal qualities. }\end{array}$ \\
\hline Results: & $\begin{array}{l}\text { The results of the study confirmed our hypothesis that athletes of various sports may experience } \\
\text { specific features of self-reliance. It has been established that self-reliance level is higher than average } \\
\text { for representatives of combat and complex-coordinated sports. Representatives of cyclical and speed- } \\
\text { strength sports are characterized with an average self-reliance level. Combat and complex-coordination } \\
\text { sports are very similar according to the specifics of self-reliance expression. Self-reliance possibility data } \\
\text { comparison among cyclical and speed-strength athletes showed their certain homogeneity. It has been } \\
\text { revealed that only a future activities reflection is closely related to a self-reliance among boxers (Spearman } \\
\text { rank correlation = -.478). There are two correlations in the sample of gymnastics representatives. An } \\
\text { increase in the overall reflection index (Spearman rank correlation = -.489) and the future activities } \\
\text { reflection index (Spearman rank correlation = -.427) leads to self-reliance decrease among gymnasts. } \\
\text { The inhibitory effect of future activity reflection on the athletes' self-reliance level has been established } \\
\text { empirically. We determined that self-assessment is a personal formation that actualizes self-reliance of } \\
\text { swimmers and discus throwers. (Spearman rank correlation }=.618 \text { ). }\end{array}$ \\
\hline Conclusions: & $\begin{array}{l}\text { The handled comparative analysis of self-reliance of different sports athletes has verified its high } \\
\text { informative value. Statistically significant differences recorded in the self-reliance level among of boxing, } \\
\text { gymnastics, discus throwing and swimming athletes. The high informative value of used questionnaire } \\
\text { allows recommending it as a screening tool during promising athletes selection. }\end{array}$ \\
\hline & \\
\hline
\end{tabular}

\section{Introduction}

The training of high-level athletes depends on many conditions: economic support, organization of training and competitive processes, material incentives, planning, selection, rehabilitation, medical support and popularity of the sport. Obviously, the significance of these conditions is different. Nevertheless, the ascent to the outstanding result in sports is impossible without systematic, structured and thoughtful psychological preparation aimed at the personality formation. This ensures the success and stability of competitive activity $[1,2]$. Research results $[3,4,5]$ convincingly demonstrate that self-reliance is the most constant factor that distinguishes successful and unsuccessful athletes.

It should be noted that confidence phenomenon has been investigated by scientists since the 20 th century. G. Mohlenkamp [6] divided confidence into: 1) related to the situation objective characteristic- «cognitive uncertainty» and 2) affective response to «cognitive uncertainty»-

\footnotetext{
(c) Kolosov A.B. , Volianiuk N.Yu., Lozhkin G.V., Buniak N.A.,

Osodlo V.I., 2019

doi:10.15561/18189172.2019.0401
}

tolerance to cognitive uncertainty. The real mechanism of action is considered as the interaction of these two types of confidence, which is based on self-reliance.

Sports psychologists define confidence as an athlete's belief in successful performance. In other words, the confidence of an athlete is nothing but his expectation of success. The powerful influence of expectations on different activities including sports is well known. It is very easy to lose confidence after several failures. Having lost to your opponent several times in a row develops doubts as well. Such negative expositions can affect future results and also the perception of uncertain behavior by others. Maintaining confidence in negative conditions is of a great importance for athletes and depends on selfreliance.

Confidence is not only an instrumental quality that determines the success and effectiveness of training and competitive activities. It contributes to the processes of self-development and self-improvement of the athlete's personality. Therefore, it has to be studied systemically and multi-dimensionally. Existing works consider confidence from different perspectives, but they lack data 
on the role of self-reliance or in other words, the trust to myself.

The possibility of self-reliance studying is of particular interest. It is one of the personal correlates within the athlete's confident behavior in such context. Self-reliance allows full realizing of the true genetic potential [7]. The athlete, who trusts himself, is able to set goals, feel his own needs and realize his potential. Such athletes take a certain valuable position in relation to themselves.

There is an undoubted semantic and etymological proximity between phenomena of self-reliance, self-faith and self-confidence. It is proven by an analysis of the research state in the psychology field of trust. However, as shown by researchers [8], these intrapersonal constructs are in complex and ambiguous relationships.

The phenomenon of self-reliance qualifies figuratively as a «category of increased complexity» in psychology [9]. E. Erickson considers trust and distrust as basic feelings, determining the development of almost all the basic relations of an individual to himself, to other people and to the world as a whole in the future [10].

Many modern researchers [11, 12] rightly argue that self-reliance should be understood as a complex, multidimensional psycho-psychological phenomenon. It includes the ability to set goals and listen to your deep inner feelings and intuitions and to choose strategies for achievements in accordance with their values.

It should be noted that a significant number of theoretical and empirical researches focuses on determining the conditions and mechanisms for athlete's confident behaviour formation [13, 14, 15].

Confidence is considered on a personal and situational level. On the one hand, confidence is understood as a property of a person, which is expressed in the acceptance of oneself, actions, decisions, and skills, as relevant and adequate. In this case it is stated about the confidence of an athlete in himself. On the other hand, confidence can be expressed in his judgments about how he solves various problems: sensory, perceptual, mnemic and cognitive. Confidence in a judgment is understood as a characteristic of decision making, i.e. select one of the competing alternatives [16].

Two levels in situational confidence should be distinguished. These are sensory level (discrimination of stimuli) and level of knowledge (general awareness). The distinction between incentives lies in the directly sensual reflection of objective reality and its visual representation to the athlete. Perception is the process of building a sensory image, or the transformation of the properties and events of reality into the inner property of the subject. Thanks to perception, an athlete is oriented in reality and preserves himself as integrity.

Self-confidence is considered as an interrelation of cognitive, behavioural, motivational and emotionalvolitional components [17]. The cognitive component is the knowledge of own strengths and capabilities associated with the development of physical qualities, mastery of equipment and tactics. This is a positive self-realization and positive attitudes towards yourself. Behavioural component is formed by an adequate experience of participation in responsible competitions. Stereotypes of confident behaviour and sets of skills and techniques for overcoming difficulties also form behavioural component. Claims and motive for success are motivational. A clear manifestation of feelings and emotions, adequate selfesteem and volitional self-control form the emotionalvolitional component.

Other authors have made similar findings. Sportconfidence is described as the belief or degree of certainty that individuals possess about their ability to success in sport [18].

Therefore, forming confident behaviour of students, the coach first of all has to find out the degree of athlete's confidence in himself. This is done by analysing deepest feelings, sensations, ideas, doubts and phobias.

However, it should be noted that most of the works in sports psychology are devoted to the study of athletes' confidence. Unfortunately, the available reference materials do not have systematic knowledge about the features of the manifestation of self-reliance among athletes of various sports.

The hypothesis of the study - qualified athletes of various sports may experience specific features of selfreliance.

The purpose of the work is to identify the features of the manifestation of self-reliance among qualified athletes of different sports.

\section{Material and Methods}

Participants:

The representatives of combat sports (boxing) $\mathrm{n}=$ 23 , complex-coordination (gymnastics) $n=25$, speedstrength (discus throw) $\mathrm{n}=23$ as well as cyclic sports (swimming) $\mathrm{n}=38$, took part in the study. The overall number of participants was 109 sportsmen. Subjects age 16-18 years old. The levels of subjects' qualification are candidate and master of sports.

\section{Research Design.}

Comprehensive psycho-diagnostic methods used in the work to diagnose self-reliance level and the degree of manifestation of athletes' personal qualities. In order to study self-reliance Astanina's questionnaire was used [19]. The method consists of 15 items. Each of these items contains statements presented in three different versions. First one is in the form of conclusions that make up the content of self-reliance cognitive component. Second one is in the form of a description of emotional experiences. Third one is in the form of behavior in meaningful or uncertain situations. Each item is represented by two opposite statements, one of which is proposed to be selected and evaluated using a bipolar graded seven-point scale. The overall self-reliance indicator is calculated by summing up points on all items. Following methods were used in the work to study personal qualities. The questionnaire of subjective control of Bazhina, Golynkin, Etkind, the method of self-assessment of personality of Budassi and the questionnaire of reflexivity by Karpova [20]. 
Statistical Analysis.

The research results are processed by the methods of mathematical statistics. These methods are the calculation of the average data, standard deviation and correlation analysis. The Pearson criterion, the Kolmogorov-Smirnov criterion, and the Student's t-criterion were used for two empirical distributions comparison. The data processing package SPSS 17.0. was used for data processing.

\section{Results}

The results of an empirical study of self-reliance among qualified athletes are presented in tables 1, 2, 3 .

It can be seen that there are no statistically significant differences in the level of self-reliance between the boxers and gymnasts from the results presented in table 1. Empirically found that the athletes of these sports have an inherent level of trust above the average. This level of self-reliance allows them to adequately assess their mental, technical and tactical resources and capabilities. It also ensures the use of verified relationships and methods of reaction in certain classes of competitive situations. The above-average level of self-reliance makes it possible to accurately assess the situation and choose the appropriate way of reacting. In our opinion the actualization of a sufficiently high level of self-reliance in combat sports is due to certain specific conditions. Firstly, training and competitive activity requires tough contact interaction with a rival. Secondly the factor of time limit demands quick decisions and the need to monitor the progress of the fight every second (boxing). Gymnastics are distinguished from all other sports by their complex coordination movements, skills and aesthetics that athletes should demonstrate. Other sports pay more attention to strength, speed and endurance. Gymnastics emphasis is placed on excellent coordination, the ability to maintain balance and at the same time make aesthetically complex movements in their performance. The fixed level of selfreliance allows managing consciously emotions, thoughts, and behavior in complex-coordination sports

Self-reliance study results of the cyclic and speedstrength sports athletes are presented in table 2 .

Comparison of the self-reliance data among cyclical and speed-strength athletes showed their certain homogeneity. The data obtained allow us to estimate the level of self-reliance among cyclical and speedstrength sports athletes as optimal. Here the demand for a high level of self-reliance is most likely limited by the specific conditions of a competitive activity. The basis of an individual athlete potential development lies in the contradictions between his needs and environmental conditions and the possibilities of their satisfaction. If these contradictions are minor, the person is adapted to the environment, and the basic needs are met in a natural way. Then there are no grounds for showing self-reliance or instead the lack of self-reliance. In such conditions, only a person, immanently possessing the impulse of creativity, continues to search for non-standard ways of solving standard tasks.

A comparative analysis of self-reliance in athletes of different sports is presented in table 3 .

From the results presented in Table 3, it can be seen that statistically significant differences in the level of selfreliance are recorded between participated representatives. The first two are combined by the nature of interaction with an opponent and the difficulty of performing actions by an athlete [21]. Two other groups are combined by the cyclical nature of repetition movements of the body in space. It has been revealed for the whole sample: the so-

Table 1. Features of the manifestation of self-reliance from representatives of combat sports and complex-coordination sports

\begin{tabular}{|c|c|c|c|c|c|c|}
\hline Parameter & Sports & $\mathbf{N}$ & Mean & Std. Deviation & $\begin{array}{l}\text { Differences } \\
\mathbf{T}\end{array}$ & $\mathbf{P}$ \\
\hline & Combat sports (boxing) & 23 & 74.78 & 7.89 & & \\
\hline Self-reliance & $\begin{array}{l}\text { Complex-coordination } \\
\text { (gymnastics) }\end{array}$ & 25 & 73.92 & 8.12 & 0.524 & 0.605 \\
\hline
\end{tabular}

Table 2. Features of self-reliance manifestation of athletes of cyclical and speed-strength sports

\begin{tabular}{lllllll}
\hline Parameter & Sports & N & Mean & Std. Deviation & $\begin{array}{l}\text { Differences } \\
\mathbf{T}\end{array}$ & P \\
\hline \multirow{2}{*}{ Self-reliance } & $\begin{array}{l}\text { Cyclical (swimming) } \\
\text { Speed-strength (discus } \\
\text { throw) }\end{array}$ & 38 & 55.26 & 3.24 & & 0.122 \\
\hline
\end{tabular}

Table 3. Comparative analysis of self-reliance in athletes of different sports

\begin{tabular}{|c|c|c|c|c|c|c|}
\hline Parameter & Sports & $\mathbf{N}$ & Mean & Std. Deviation & $\begin{array}{l}\text { Differences } \\
T\end{array}$ & $\mathbf{P}$ \\
\hline \multirow[t]{2}{*}{ Self-reliance } & $\begin{array}{l}\text { Combat sports, complex- } \\
\text { coordination }\end{array}$ & 48 & 74.35 & 7.7 & \multirow[b]{2}{*}{-11.744} & \multirow[b]{2}{*}{0.000} \\
\hline & Cyclic, speed-power & 61 & 54.84 & 2.88 & & \\
\hline
\end{tabular}


called «optimal» level of self-reliance is a characteristic, which allows setting realistic goals, criticizing yourself, feeling your own needs and realizing your potential. This optimum of self-reliance is one of the indicators of both the maturity of an athlete and his mental well-being.

The logic of our research also included the study of personal bases of self-reliance among athletes of different sports. The survey results are presented in tables 4 and 5 .

An analysis of the data from a sample of highly qualified athletes showed the following results. Among the respondents, the majority has an internal locus of control, a favorable, positive attitude towards themselves and an optimal level of reflection.

Results from table 4 and 5 show that between athletes performing differently structured activities, statistically significant differences were found in multiple terms. These are general internality, internality in failures, internality in business relationships, reflection of the present activity and reflection of communication and relationship. Locus of control is a rather common concept in modern psychology. This hypothetical personality construct was introduced into the scientific flow of psychological science in 1954 by J. Rotter [22]. The level of subjective control gives a generalized characteristic of autonomy, responsibility and independence of an individual. It also describes the extent to which a person feels as an active subject of his own activities, or as a passive object of other people's actions and external circumstances. The locus of control is a bipolar characteristic. Internals are on one pole, externalities are on the other. Persons who take responsibility for the events of their lives have internal control.

Events are explained with their behavior, abilities and character traits according to the locus of control concept (from Latin. Locus - «place, location»). And vice versa, people who are inclined to attribute responsibility for all events to external factors (other people, destiny, situations, etc.), have external control. Deviation to the right from the result obtained $(\geq 5.5)$ indicates an internal type of control in different life situations in accordance with the used questionnaire. Deviation to the left $(\leq 5.5)$ indicates the external type of control localization.

From Table 5 it can be seen that, in terms of the «total internality» the difference at the $5 \%$ level were established. Representatives of combat sports and complex-coordinating sports can be characterized as internals. This means they are more self confident and less anxious. They are independent, with a heightened sense of responsibility for their own actions. According to the indicators of «internality in failures» and «internality in business relations» between boxers, gymnasts, swimmers and discus throwers there were established differences of $1 \%$ and $5 \%$. Probably, the involvement of athletes in sports with a complex technical and motor organization is a resource for increasing their own responsibility for their failures in training and competitive activities.

Reflection is a focal point in the regulation of mental states [23]. With its help, awareness, assessment and comparison of the current state with the desired one are carried out. Reflection allows the athlete to predict possible options and results of the regulation of mental states in different situations of training and competitive activity. It also allows restructuring existing methods of action, and analyzing those actions that do not lead to success. The main psychological mechanism of reflection, which determines the transforming and integrative functions, is the internal dialogue [24]. Results in Table 5 showed $1 \%$ and $5 \%$ level difference between «reflection

Table 4. Features of the manifestation of personal qualities of athletes of different sports

\begin{tabular}{|c|c|c|c|c|}
\hline \multirow{3}{*}{ Parameter } & \multicolumn{4}{|l|}{ Sports } \\
\hline & $\begin{array}{l}\text { Combat } \\
\text { sports }\end{array}$ & $\begin{array}{l}\text { Complex- } \\
\text { coordination }\end{array}$ & Cyclic & $\begin{array}{l}\text { Speed-power } \\
\text { sports }\end{array}$ \\
\hline & $\begin{array}{l}\text { Mean } \pm \text { Std. } \\
\text { Deviation }\end{array}$ & $\begin{array}{l}\text { Mean } \pm \text { Std. } \\
\text { Deviation }\end{array}$ & $\begin{array}{l}\text { Mean } \pm \text { Std. } \\
\text { Deviation }\end{array}$ & $\begin{array}{l}\text { Mean } \pm \text { Std. } \\
\text { Deviation }\end{array}$ \\
\hline Total internality & $5.85 \pm 1.59$ & $5.98 \pm 1.64$ & $4.93 \pm 1.89$ & $4.91 \pm 2.02$ \\
\hline Internality in achievements & $6.37 \pm 1.56$ & $6.52 \pm 1.66$ & $6.16 \pm 2.15$ & $6.10 \pm 2.15$ \\
\hline Internality in failures & $5.69 \pm 1.97$ & $5.76 \pm 1.95$ & $4.24 \pm 1.63$ & $4.54 \pm 1.62$ \\
\hline Internality in family relationships & $5.60 \pm 1.47$ & $5.82 \pm 1.59$ & $5.17 \pm 1.67$ & $5.08 \pm 1.65$ \\
\hline Internality in business relations & $5.04 \pm 1.63$ & $5.24 \pm 1.75$ & $3.84 \pm 2.02$ & $3.78 \pm 2.26$ \\
\hline $\begin{array}{l}\text { Interpersonal relationships } \\
\text { internality }\end{array}$ & $6.02 \pm 0.983$ & $6.00 \pm 0.94$ & $5.89 \pm 0.88$ & $6.00 \pm 0.94$ \\
\hline Internality for health and disease & $4.65 \pm 2.02$ & $4.80 \pm 2.11$ & $5.22 \pm 2.18$ & $5.08 \pm 2.21$ \\
\hline General level of reflection & $130.65 \pm 16.00$ & $131.32 \pm 16.34$ & $138.79 \pm 17.48$ & $138.65 \pm 16.91$ \\
\hline Retrospective reflection & $36.43 \pm 4.51$ & $36.36 \pm 4.44$ & $36.08 \pm 4.03$ & $36.00 \pm 4.07$ \\
\hline Reflection of the present activity & $37.22 \pm 5.27$ & $37.24 \pm 5.29$ & $32.26 \pm 5.85$ & $32.91 \pm 5.99$ \\
\hline Reflection of future activities & $37.09 \pm 5.79$ & $37.12 \pm 5.57$ & $37.26 \pm 7.03$ & $35.91 \pm 6.34$ \\
\hline $\begin{array}{l}\text { Reflection of communication and } \\
\text { relationships }\end{array}$ & $39.13 \pm 4.96$ & $39.08 \pm 4.76$ & $35.34 \pm 6,07$ & $35.83 \pm 6.63$ \\
\hline Self esteem & $0.639 \pm 0.22$ & $0.644 \pm 0.21$ & $0.497 \pm 0.22$ & $0.51 \pm 0.23$ \\
\hline
\end{tabular}


of the present activity» and «reflection of communication and relationships» for the tested sample. For boxers and gymnasts a higher level of activation of the semantic structures of consciousness ensures the development of techniques, tactics and principles of the training process.

Correlation analysis was used in the work to identify personal qualities that determine self-reliance among athletes, It has been revealed that among boxers only a reflection of future activities is closely related to selfreliance ( $\left.r_{s}=-0.478 ; P \leq 0.05\right)$. In the sample of gymnasts there are two correlations. Thus, an increase in the overall reflection index $(\mathrm{rs}=-0.489 ; \mathrm{P} \leq 0.05)$ and the reflection index of future activities $\left(\mathrm{rs}_{\mathrm{s}}=-0.427 ; \mathrm{P} \leq 0.05\right)$ leads to a decrease in self-reliance.

It has been established that self-esteem is a personal formation that actualizes self-reliance for swimmers and discus throwers $(\mathrm{rs}=0.618 ; \mathrm{P} \leq 0.01)$. This correlation indicates self-assessment as an important personality trait. It provides athlete's assessment of his physical and mental qualities, achievements and failures, strengths and weaknesses. The efficiency of the holistic process of regulating sports activities to the maximum extent is also provided by this trait.

\section{Discussion}

The main purpose of this study was to identify the features of self-reliance manifestation among qualified athletes of different sports. The results of the study confirmed our hypothesis that athletes of various sports may experience specific features of self-reliance. Personality characteristics comparison of athletes in different disciplines is widely used in sport science. This allows estimating sport influence specificity. It identifies the most informative indicators and justifies selection criteria and successfulness projection criteria. This analysis allows defining the sport influence specificity at the psyche. The literature search was systematic and comprehensive.

The scientific literature presents the analysis results of interpersonal trust in the team and trust of athletes to the coach $[25,26]$. However, self-reliance among athletes of various sports has not been investigated. A reliable and valid methodology was selected for the study of selfreliance (author Astanina). The method is designed on the basis of the semantic differential. It consists of 15 items, each containing statements presented in three different ways. As a reasoning that constitute the cognitive component of reliance in own self. As a description that constitute emotional experiences and behavior in important situations and situations of uncertainty. The high informative value of used questionnaire allows recommending it as a screening tool for promising athletes selection.

It has been established that self-reliance level is higher than average for representatives of combat and complex-coordinated sports. Representatives of cyclical and speed-strength sports are characterized with an average self-reliance level. Absolutization of self-reliance leads to decrease in athletic performance and destroys the moral and ethical regulators of behavior. It forms permissiveness and reduces criticality towards oneself. Such quality was not traced in this sample of athletes. This reaffirms that there is a complex, inverted U-shaped relationship between the self-reliance level and the sports

Table 5. Statistically significant differences in the development level of personal qualities among athletes of different sports

\begin{tabular}{|c|c|c|c|c|}
\hline \multirow[t]{2}{*}{ Parameter } & \multicolumn{2}{|l|}{ Respondents } & \multicolumn{2}{|c|}{ Differences } \\
\hline & Sport & Sport & $T$ & $P$ \\
\hline \multirow{4}{*}{ Total internality } & Combat sports & Speed-power & -2.14 & 0.05 \\
\hline & Complex coordination & Cyclic & -2.10 & 0.05 \\
\hline & Complex coordination & Speed-power & -2.43 & 0.05 \\
\hline & Combat sports & Speed-power & -2.50 & 0.05 \\
\hline \multirow{4}{*}{$\begin{array}{l}\text { Internality in } \\
\text { failures }\end{array}$} & Combat sports & Cyclic & -3.15 & 0.01 \\
\hline & Complex coordination & Speed-power & -2.71 & 0.01 \\
\hline & Complex coordination & Cyclic & -3.30 & 0.01 \\
\hline & Combat sports & Speed-power & -2.62 & 0.05 \\
\hline \multirow{4}{*}{$\begin{array}{l}\text { Internality in } \\
\text { business relations }\end{array}$} & Combat sports & Cyclic & -2.30 & 0.05 \\
\hline & Complex coordination & Speed-power & -2.92 & 0.01 \\
\hline & Complex coordination & Cyclic & -2.64 & 0.05 \\
\hline & Combat sports & Speed-power & -2.99 & 0.01 \\
\hline \multirow{3}{*}{$\begin{array}{l}\text { Reflection of the } \\
\text { present activity }\end{array}$} & Combat sports & Cyclic & -3.04 & 0.01 \\
\hline & Complex coordination & Speed-power & -3.07 & 0.01 \\
\hline & Complex coordination & Cyclic & -3.11 & 0.01 \\
\hline \multirow{4}{*}{$\begin{array}{l}\text { Reflection of } \\
\text { communication and } \\
\text { relationships }\end{array}$} & Combat sports & Speed-power & -2.22 & 0.05 \\
\hline & Combat sports & Cyclic & -2.32 & 0.05 \\
\hline & Complex coordination & Speed-power & -2.33 & 0.05 \\
\hline & Complex coordination & Cyclic & -2.42 & 0.05 \\
\hline
\end{tabular}


result [16]. Sport results rise with an increase in the level of self-reliance to the optimum. Following increase in self-reliance can lead to a corresponding decrease.

The study revealed the severity of personality determinants (locus of control, self-esteem, reflection) and their connection with self-reliance among athletes. It has been found that among boxer's personal qualities, only the reflection of future activities is closely related to self-reliance (Spearman rank correlation $=-.478$ ). In the gymnasts sample there are two correlations. An increase in the general index of reflection (Spearman rank correlation $=-.489$ ) and the index of reflection of future activities (Spearman rank correlation $=-.427$ ) leads to a decrease in self-reliance. The higher the level of conscious and arbitrary processes of reflection, than the lower the level of self-reliance of an athlete. Excessive elaboration and prediction of the results of future activities acts as a «trigger». That launches contradictory trends and negative feelings about the understanding, acceptance and evaluation of oneself. However, other arguments, in particular those that can be explained by Festinger's theory of cognitive dissonance, come to the fore here [27]. Dissonance is a state of internal discomfort. It's caused by contradictions between the stable representations of the individual and new facts and conditions. This feeling creates the desire to stimulate reflection in order to verify the truth of the new information. Cognitive dissonance determines the state of the personality, which is characterized by inconsistency and contradictory views. Most often, inconsistencies arise on the basis of ideological, professional and value beliefs. The theory of cognitive dissonance characterizes ways to smooth out these contradictions and describes how a person does this in typical situations. When a contradiction appears between the content of the elements then motivational effects arise. They are generated by the tendency to harmonize. In our opinion, this explains the high aspirations of well-qualified athletes to reflective activity. This results in harmony, consistency of representations of the external world and oneself. But on the other hand it also decreases self-reliance.
The inhibitory effect of future activity reflection on the self-reliance level among athletes has been established empirically. An analysis of the data from a sample of highly qualified athletes showed the following results. The majority of respondents have an internal locus of control, a favorable positive attitude towards themselves and an optimal level of reflection. However, there was no significant correlation between the locus of control and self-reliance among athletes.

Self-esteem of cyclical and speed-strength sports athletes is a personal formation that actualizes selfreliance (Spearman rank correlation $=.618$ ). This correlation indicates that self-esteem is an important personality trait. It provides athlete's assessment of his physical and mental qualities, achievements and failures, strengths and weaknesses. The efficiency of the holistic process of regulating sports activities to the maximum extent is also provided by this trait.

\section{Conclusions}

Self-reliance is a complex construct that can be recognized in a reflective work with oneself. This intrapersonal construct can be empirically measured. Sports performance rises with an increase in the level of self-reliance to the optimum. The handled comparative analysis of self-reliance of different sports athletes has verified its high informative value. It has been established that the level of trust in oneself is higher than average for boxers and gymnasts. Swimmers and discus throwers are characterized by an average level of trust in oneself. The high informative value of used questionnaire allows recommending it as a screening tool for promising athletes selection. The higher the level of conscious and arbitrary processes of reflection, than the lower the level of selfreliance of an athlete. Self-esteem is a personal formation that actualizes self-reliance.

\section{Conflicts of interest:}

The authors declare that they have no conflicts of interest.

\section{References}

1. Gould D, Weiss V, Weinberg R. Psychological characteristics of successful and non successful Big Ten wrestlers. Journal of Sport psychology, 1981; 3:69-81. https://doi.org/10.1123/jsp.3.1.69

2. Lochbaum M, Zazo R, Kazak Cetinkalp Z, Graham $\mathrm{K}$, Wright $\mathrm{T}$, Konttinen N. A meta-analytic review of achievement goal orientation correlates in competitive sport: A follow-up to Lochum et al. Kinesiology. 2016;48: 159-73. https://doi.org/10.26582/k.48.2.15

3. Ryska TA. Self-esteem among intercollegiate athletes: The role of achievement goals and competitive orientation. Imagination, Cognition and Personality, 2002; 21(1): 67-80. https://doi.org/10.2190/D6R7-KGFM-HALC-UPB7

4. Vealey RS. Conceptualization of sport-confidence and competitive orientation: Preliminary investigation and instrument development. Journal of Sport Psychology.1986; 8:221-246. https://doi.org/10.1123/jsp.8.3.221

5. Volianiuk NYu, Lozhkin GV. Predictors of confidence in conditions of uncertainty. In: Collection of articles based on the VI International Scientific Practical Conference "Psychological support of education: theory and practice», Joshkar-Ola, December 24-26, 2015, Joshkar-Ola; 2016. P. 71-75. (in Russian)

6. Mohlenkamp G. Kreative Bewältigung kognitiver Unsicherheit. Die Motivationalen Voraussetzungen unterschiedlicher Bewaltingnusstrateigien kognitiver Konflikt: ein theoreicher Entwurf und der Versuch seiner empirichen Validierung [Coping with cognitive uncertainty. The Motivational Prerequisites of Different Attacking Cognitive Conflict: A Theoretical Design and the Trial of its Empirical Validation], Munster; 1975. (in German)

7. Emerson R. Toward a Theory of Value in Social Exchange. Social Exchange Theory; 1987.

8. Kupreichenko AB. Psychology of trust and distrust. Moscow: 
Publishing House «Institute of Psychology of the Russian Academy of Sciences»; 2008. (in Russian)

9. Skripkina TP. Self-reliance as a condition for personal development. Voprosy psikhologii, 2002;1:95-103. (in Russian)

10.Erikson EH. Insight and responsibility. New York: Norton; 1964.

11.Emerson R. Moral Philosophy. Minsk: Harvest, Moscow: AST; 2001. (in Russian)

12.Hoffinan A. A conceptualization of trust in international relations. European journal of international relation, 2002; 8 (3): 375-401. https://doi.org/10.1177/1354066102008003003

13.Nandal M. A comparative study of self-confidence among Hockey and Volleyball Players. Darpan Communication Society. 2014;1(12):44.

14. Woodman T, Hardy L. The relative impact of cognitive anxiety and self-confidence upon sports performance: A meta- analysis. Journal of Sports Sciences, 2003;21:443-457. https://doi.org/10.1080/0264041031000101809

15.Covassin T, Pero S. The relationships between selfconfidence, mood state, and anxiety among collegiate tennis players. Journal of sport behavior, 2003;3:230-242.

16. Weinberg RS, Gould D. Foundations of Sport and Exercise Psychology. Champaign, Human Kinetics;2003.

17.Seligman A. The problem of trust. Moscow: Ideya-Press; 2002. (in Russian)

18. Wilson RC, Sullivan PJ, Myers ND, Feltz DL. Sources of Sport Confidence of Master Athletes. $J$ Sport Exerc Psychol. 2004;26(3):369- 84. https://doi.org/10.1123/jsep.26.3.369
19.Astatina NB. Creation and approbation of a new personal questionnaire "Methods of studying of self-reliance». Psychological Science and Education; [Internet]. 2010 [cited 2019 Jan 23];3. Available from: http://psyedu.ru/ journal/2010/3/Astanina.phtml (in Russian)

20.Rean AA. Psychology and personality psychodiagnostics: theory, research methods, practical work. Saint Petersburg: Prime EUROPEAN; 2008. (in Russian)

21.El-Ashker S, Nasr M. Effect of boxing exercises on physiological and biochemical responses of Egyptian elite boxers. J Phys Ed Sport, 2012;12:111-116.

22.Rotter JB. Interpersonal trust, trustworthiness, and gullibility. American Psychologist, 1980; 35:1-7. https://doi.org/10.1037/0003-066X.35.1.1

23.Prokhorov AO, Chernov AV. The role of reflection in the process of regulation of students' mental states. In: V.A. Drummers. ed. Natural-scientific approach in modern psychology. Moscow: Publishing House Institute of Psychology of the Russian Academy of Sciences; 2014. P.783-788. (in Russian)

24.Karpov AV. Regularities of the structural organization of reflexive processes. Psychological Journal, 2006;6:8-28. (in Russian)

25.Martens R. Successful coaching. Moscow: Man; 2014. (in Russian)

26.Thompson P. Introduction to coaching theory. Moscow: Man; 2014. (in Russian)

27.Festinger L. Introduction to the theory of dissonance. In. Festinger L. Theory of cognitive dissonance. St. Petersburg: Yuventa; 1999. (in Russian)

\section{Information about the authors:}

Kolosov A.B.; PhD.; http://orcid.org/0000-0001-6834-940X; andriy_kolosov@i.ua; Laboratory of Current and Operative Control of National Teams' Performance, State Scientific Research Institute of Physical Culture and Sports; 19, Stolychne Shose, 03131, Kyiv, Ukraine.

Volianiuk N.Yu.; (Corresponding author); Professor, Dr.; http://orcid.org/0000-0001-6945-5984; n.volianiuk1@gmail.com; Department of Psychology and Pedagogy, National Technical University of Ukraine «lgor Sikorsky Kyiv Polytechnic Institute»; 37 Peremogy Avenue, 03056 Kyiv, Ukraine.

Lozhkin G.V.; Professor, Dr.; http://orcid.org/0000-0002-6705-9344; lozhkin35@gmail.com; Department of Psychology and Pedagogy, National Technical University of Ukraine «Igor Sikorsky Kyiv Polytechnic Institute»; 37 Peremogy Avenue, 03056 Kyiv, Ukraine.

Buniak N.A.; Professor, Dr.; http://orcid.org/0000-0002-1129-6623; bunjak_n@tntu.edu.ua; Department of Psychology in production Ternopil Ivan Puluj National Technical University, Ruska str., 56, 46000 Ternopil, Ukraine.

Osodlo V.I.; Professor, Dr.; http://orcid.org/0000-0003-2893-4721; v.osyodlo@gmail.com; Social Studies Institute, National Defence University of Ukraine named after Ivan Cherniakhovskyi; Povitroflotskyi Pr., 28, 03049 Kyiv, Ukraine.

Cite this article as:

Kolosov AB, Volianiuk NYu, Lozhkin GV, Buniak NA, Osodlo VI. Comparative analysis of self-reliance of athletes of different sports. Pedagogics, psychology, medical-biological problems of physical training and sports, 2019;23(4):162-168. https://doi.org/10.15561/18189172.2019.0401

This is an Open Access article distributed under the terms of the Creative Commons Attribution License, which permits unrestricted use, distribution, and reproduction in any medium, provided the original work is properly cited (http://creativecommons.org/licenses/by/4.0/deed.en).

Received: 14.04.2019

Accepted: 22.05.2019; Published: 29.08.2019 